\title{
Countries' Progress and
} Enablers for Circular Carbon Economies 


\section{About KAPSARC}

The King Abdullah Petroleum Studies and Research Center (KAPSARC) is a non-profit global institution dedicated to independent research into energy economics, policy, technology and the environment across all types of energy. KAPSARC's mandate is to advance the understanding of energy challenges and opportunities facing the world today and tomorrow, through unbiased, independent, and high-caliber research for the benefit of society. KAPSARC is located in Riyadh, Saudi Arabia.

This publication is also available in Arabic.

\section{Legal Notice}

(c) Copyright 2021 King Abdullah Petroleum Studies and Research Center ("KAPSARC"). This Document (and any information, data or materials contained therein) (the "Document") shall not be used without the proper attribution to KAPSARC. The Document shall not be reproduced, in whole or in part, without the written permission of KAPSARC. KAPSARC makes no warranty, representation or undertaking whether expressed or implied, nor does it assume any legal liability, whether direct or indirect, or responsibility for the accuracy, completeness, or usefulness of any information that is contained in the Document. Nothing in the Document constitutes or shall be implied to constitute advice, recommendation or option. The views and opinions expressed in this publication are those of the authors and do not necessarily reflect the official views or position of KAPSARC. 


\section{Key Points}

he circular carbon economy (CCE) is a new concept, developed in detail by Saudi scholars and stakeholders since 2019 and promoted via Saudi Arabia's Group of Twenty (G20) presidency in 2020. The CCE is conceptualized as an economy in which atmospheric carbon dioxide emissions are minimized and offset by reducing, recycling, reusing, and removing carbon. The concept emphasizes the need to address emissions holistically using all available mitigation options. It also recognizes the economic value of carbon and each country's specific circumstances.

G20 leaders endorsed the CCE in November 2020, describing it as a "voluntary, holistic, integrated, inclusive, pragmatic, and complementary approach to promote economic growth while enhancing environmental stewardship through managing emissions in all sectors" (G20 Energy Ministers 2020). Saudi Arabia is developing a national program and related strategies to demonstrate practical applications of the CCE approach. Researchers in Saudi Arabia are working to support planning and policy design by generating new data and information. Additionally, researchers and businesses are developing and piloting several CCE-related technologies in collaboration. However, more work remains to be done to increase the understanding of the concept and its utility beyond the Kingdom.

KAPSARC has initiated a project that aims to help clarify the CCE concept and promote its use as a conceptual framework for managing emissions, including as part of net-zero pathways, by countries worldwide. The project focuses on building a composite indicator to measure country performance and potential on the CCE. As part of this project, KAPSARC organized a domestic stakeholder workshop. This meeting highlighted the need for further work in two broad areas to support the transition to CCEs.

Various types of enablers are needed to help scale up CCE solutions and technologies at the organization and industry levels. Most require efforts by governments, but many can also benefit from collaborations with and between companies and researchers. These enablers include:

Investments in new technologies and energy sources, including both research and development (R\&D) and adoption;

Collaborations among governments, businesses and academia to carry out R\&D and pilot projects;

- Advocacy and dialogue in support of the necessary transitions;

Demonstrations of how a CCE approach can unlock cost-effective abatement through practical applications; and

- Establishment of measurement and accounting systems to track progress. 


\section{Key Points}

Data, metrics, accounting frameworks and standards are necessary to strengthen data-driven decision-making around CCE technology and policy choices. Making existing data available to researchers and other stakeholders is a crucial first step in this regard. Moreover, further research in many areas would be beneficial. These areas include:

- Data on other greenhouse gases, including methane, nitrous oxide and hydrofluorocarbons;

- Lifecycle analyses of various CCE technologies and products;

Data and metrics for measuring circularity performance and potential in the hydrocarbon sector

and among oil companies;

- Carbon circularity standards for industries;

- Data and metrics related to carbon (capture and) utilization; and

Data and studies on the overall cost of mitigation, including at the economy level and for

- various CCE scenarios with different combinations of circularity technologies. 


\section{Summary}

In 2021, KAPSARC began developing a composite indicator to provide a robust and objective quantitative tool for evaluating performance and progress toward circular carbon economies across countries worldwide. The first edition of the Circular Carbon Economy (CCE) Index will measure present-day performance and the enabling conditions for future progress on the CCE across 30 countries, including the G20 member countries and top oil-producing countries.

KAPSARC researchers are constructing the Index following international best practice, which includes consultation with issue experts and stakeholders. KAPSARC formally kicked off these CCE Index consultations on June 6, 2021, by convening stakeholders from government, industry and academia in a half-day virtual workshop. The workshop had two main purposes. The first was to initiate a discussion on a data-driven approach to measuring the CCE. The second was to collect inputs to inform the design of the index structure and indicators.

The workshop was structured into two sessions reflecting the two main parts of the CCE Index: performance and enablers. Scene-setting presentations and questions were provided in advance to the speakers and other participants to ensure a focused discussion. A KAPSARC Methodology Paper (Luomi et al. 2021) was also provided to the participants ahead of the session to help guide the discussions.

Both the presentations and the discussions among the workshop participants provided important inputs for further developing the CCE Index, particularly in areas where the team had identified indicator and data gaps. These areas included indicators related to carbon capture and utilization, economic aspects of carbon valuation and mitigation, various CCE-specific enablers, and oil producer-specific CCE metrics.

This brief provides a summary of the workshop discussions on the broader theme of CCE metrics and enablers. It is divided into three sections:

\section{Current work in Saudi Arabia on CCE} planning, data and research;

Enablers for future progress on the CCE; and

Areas for further work on CCE metrics and tools to support implementation. 


\section{Background: The CCE Index}

7 APSARC's Circular Carbon Economy (CCE) Index project seeks to expand and add rigor to the conceptual basis of the CCE, as well as its practical operationalization. To do so, the project is developing a robust quantitative framework to measure country performance on, and potential to progress toward, achieving CCEs. The CCE Index is intended to enable further discussions around ways to identify, measure and compare countries' strengths and weaknesses in terms of the CCE. It can also help pinpoint the areas where progress is already well underway and those where further policy efforts are needed or may be beneficial.

\section{A KAPSARC Methodology Paper titled "The}

Circular Carbon Economy Index - Methodological Approach and Conceptual Framework" (Luomi et al. 2021) provides an overview of the methodological approach adopted for developing the Index. It also puts forth an initial conceptual framework for the set of indicators that will eventually comprise the first edition of the CCE Index. This edition will be launched in late 2021.

A workshop was held on June 6, 2021 to engage issue experts and stakeholders on further developing the CCE Index. The workshop included scene-setting presentations on the two sub-indices that comprise the CCE Index (see Figure 1).

The CCE Performance sub-index measures how countries are implementing major carbon circularity technologies and policies to minimize atmospheric carbon dioxide emissions.

The CCE Enablers sub-index measures how countries are positioned to support and enable progress toward a CCE through indicators grouped in five major areas. These areas reflect the breadth of the transformations required across technological and market structures and regulatory frameworks.

An additional set of indicators under each sub-index will be used for more in-depth comparisons among the oil-producing countries included in the index. Under the performance sub-index, these indicators will seek to measure how oil-producing countries are minimizing emissions from related industries and creating value from carbon. Under the enablers sub-index, oil producer-specific indicators will aim to measure how well countries and their major or national oil companies are managing the industry's transformation. 
Figure 1. Conceptual framework of the CCE Index as of June 6, 2021.

\section{CCE Index}

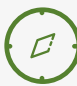

\section{CCE Performance Sub-Index}

$\rightarrow \quad$ Indicators applied to all countries
Energy efficiency
Renewable energy
Nuclear energy
Fuel switching
Natural sinks
Carbon capture and storage
Clean hydrogen
Electrification

* Grey text implies a proposed indicator for which data are not yet available or has not yet been identified.
$\mathrm{CO}_{2}$ per unit of manufacturing

$\mathrm{CO} 2$ embedded in fossil fuel exports

$\mathrm{CO} 2$ intensity of fossil fuel production

Flaring intensity of oil production

Chemical production/barrel of oil*

Carbon utilization (fertilizers, beverages, polymers)*

\section{CCE Enablers Sub-Index}

Policies, regulation, and governance

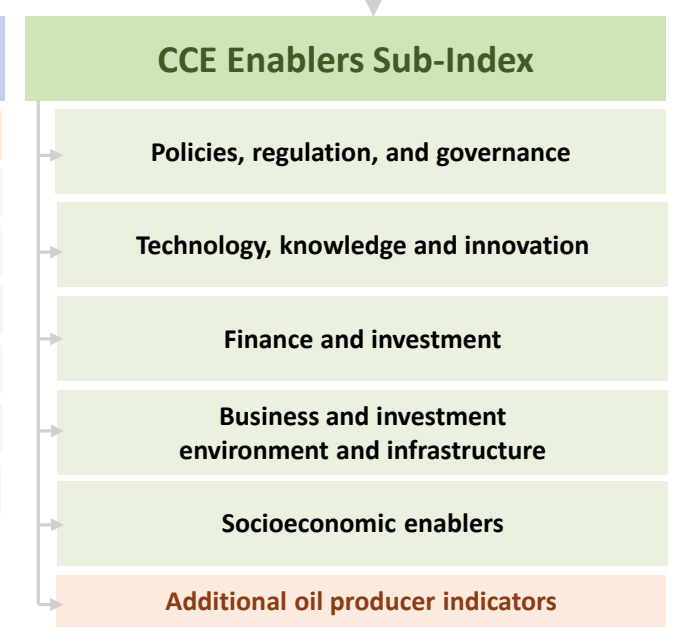

Source: KAPSARC.

The 2021 edition of the CCE Index will include 30 countries, as shown in Figure 2.

Figure 2. Countries included in the 2021 CCE Index.

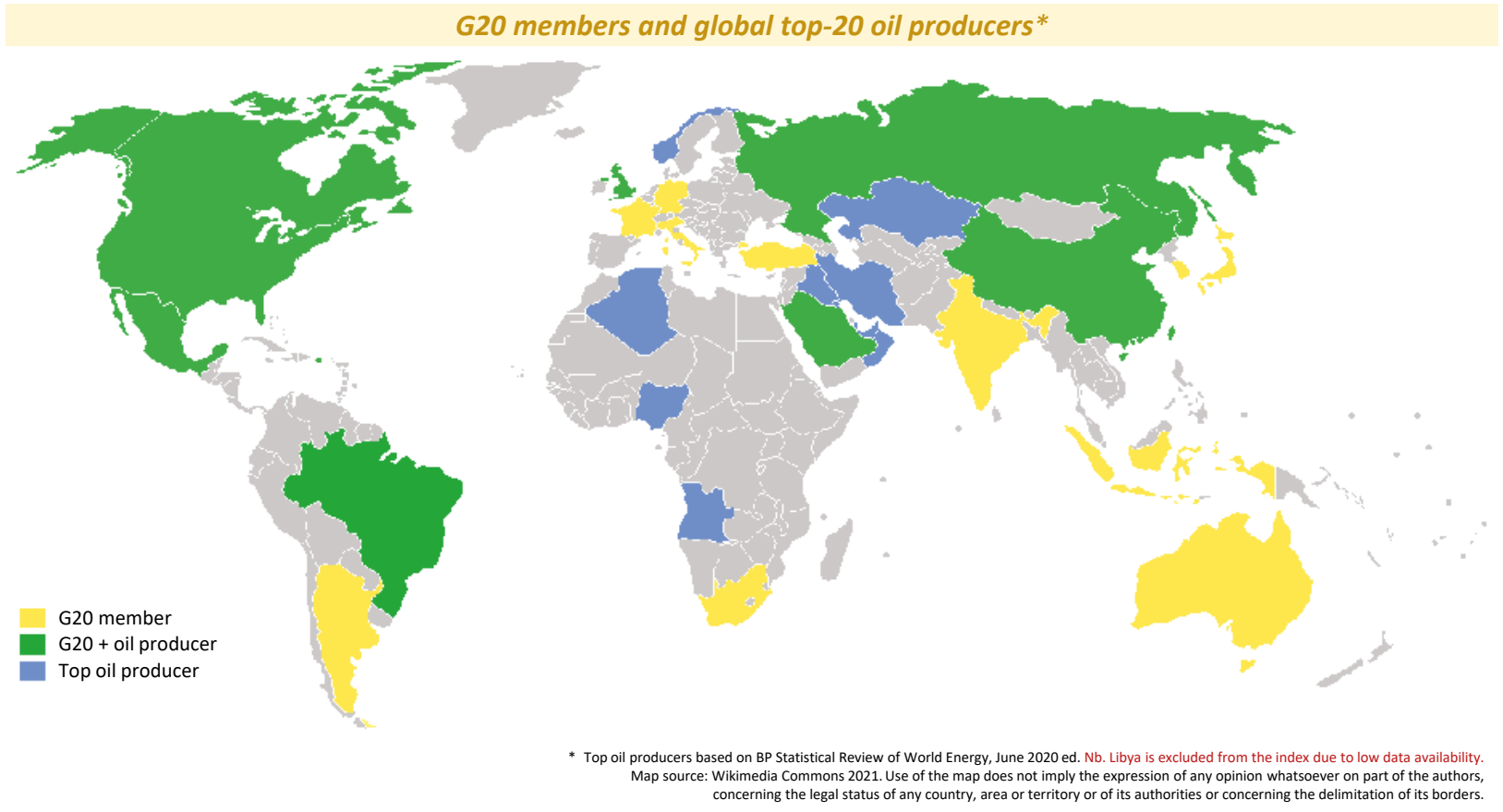

Source: KAPSARC. 


\section{Current Work in Saudi Arabia on CCE Planning, Data and Research}

The CCE emerged on Saudi Arabia's energy policy agenda in 2019. A KAPSARC paper was the first study to frame the concept in this context (Williams 2019). The paper introduced the four Rs that have come to define the holistic approach to managing emissions that best characterizes the CCE concept: reduce (including energy efficiency and renewable energy), reuse (various carbon utilization applications), recycle (either bioenergy or some other carbon utilization applications, depending on the definition adopted), and remove (including carbon capture and storage, CCS).

Different authors and institutions characterize the four Rs differently, but all refer to the same set of mitigation technologies and policies listed above. Many conceptualizations add crosscutting elements, such as hydrogen and electrification. Other commonly cited features of the CCE include an emphasis on cost efficiency and a recognition of the economic value of carbon - and not only its related environmental externalities.

The CCE's proponents also stress that countries' different circumstances and endowments will shape their paths to carbon circularity. The major value added by the CCE concept to the global climate change mitigation discussions is arguably the recognition that more attention is needed to addressing emissions in hard-to-abate sectors and in countries with large hydrocarbon endowments.

Saudi researchers and the government actively promoted the CCE throughout Saudi Arabia's 2020 presidency of the G20. The Saudi Ministry of Energy's active advocacy led to the concept's endorsement by the G20 Energy Ministers in September 2020 and later by G20 leaders in their final communiqué in November 2020 (G20 Energy
Ministers 2020; G20 Saudi Arabia 2020). At the G20 Leaders Summit, King Salman bin Abdulaziz Al Saud launched the CCE National Program, which is being developed by a dedicated team at the Ministry of Energy, through close engagement with the Saudi energy ecosystem and research institutions.

To date, the CCE National Program has developed a CCE technology map and identified existing CCE initiatives in the Kingdom. The team explored 57 key emissions reduction technologies, out of which 36 were identified as those whose implementation can be scaled up or that have potential for scaling up (Figure 3). The program team has also developed metrics and key performance indicators to measure current performance and future progress toward the CCE, based on data provided by key government institutions and industry stakeholders. In addition, the National Program has identified necessary funding mechanisms and enablers and is actively working on outreach around the concept.

Most of the existing 263 CCE-relevant initiatives in Saudi Arabia that were identified by the CCE National Program focus on the reduce pillar. Thus, a key driver of the program is to bring the remove pillar more into balance with the reduce pillar. For technologies with high potential under both pillars, the program will aim to invest in related R\&D and support the scaling up of these technologies and their commercial implementation.

Another key driver of the program is establishing a mix of technologies that ensure the lowest cost and most effective way for abating emissions. This work has prompted the development of national strategies for hydrogen and carbon capture, utilization and storage, which were identified as leading technologies with high abatement potential. Various international Paris Agreement-aligned 
scenarios indicate that hydrogen, and CCS, as well as carbon capture and utilization (CCU) can play significant roles in reducing atmospheric carbon dioxide emissions (Hepburn et al. 2020; KAPSARC 2020). However, government support will be crucial to help bring down costs and related technologies to the market.

Figure 3. Emissions reduction technologies reviewed by the CCE National Program.

\section{7 key emissions reduction technologies were scanned, $\sim 36$ of which were prioritized for immediate focus as part of the CCE national program}

\begin{tabular}{|c|c|c|c|}
\hline \multicolumn{2}{|c|}{ Reduce $11 / 29$} & \multicolumn{2}{|c|}{ Reuse $\quad 6 / 8$} \\
\hline Renewables & 5 & $\mathrm{CO}_{2}$ industrial use & 4 \\
\hline Solar & P1 & Enhanced Oil Recovery & P2 \\
\hline Wind & P1 & Enhanced geothermal & P3 \\
\hline Hydro/ marine & P3 & $\mathrm{CO}_{2}$ as a working fluid & P2 \\
\hline Energy storage & P2 & Greenhouse & P3 \\
\hline Geothermal & P3 & $\mathrm{CO}_{2}$ commercial use & 4 \\
\hline GHG-free fuels & 2 & Food \& Beverage & P2 \\
\hline Nuclear & P1 & Fire extinguishers & $\mathrm{P} 2$ \\
\hline Hydrogen & $\mathrm{P} 2$ & Refrigeration & P2 \\
\hline Energy efficiency & 6 & Medical use & $\mathrm{P} 2$ \\
\hline Demand side management & P1 & Alternative technologies & 9 \\
\hline $\begin{array}{l}\text { Equipment efficiency } \\
\text { Process changes }\end{array}$ & $\begin{array}{l}\mathrm{P} 1 \\
\mathrm{P} 1\end{array}$ & Advanced desal. technology & P1 \\
\hline WHR $1 /$ cogeneration & P1 & Kilns electrification & P2 \\
\hline $\mathrm{ICE}^{2} /$ design improvements & P1 & DRI-EAF & P3 \\
\hline Precision farming & P1 & Crude oil to chemicals & P3 \\
\hline Fuel switching & 4 & Electrification-chem. process & P2 \\
\hline Fuel sw/tching & 4 & Electric cracking in refineries & P2 \\
\hline Liquid displacement & P1 & Fugitive emissions reduction & P3 \\
\hline Zero emissions vehicles & P2 & Crop production optimization & P3 \\
\hline Natural gas powered vehicles & P3 & Livestock management & $\mathrm{P} 2$ \\
\hline Waste to energy & P2 & & \\
\hline Alternative feedstock & 3 & & \\
\hline Clinker ratio reduction & P2 & & \\
\hline Alt. cement binding material & P2 & & \\
\hline Recycling & P2 & & \\
\hline
\end{tabular}

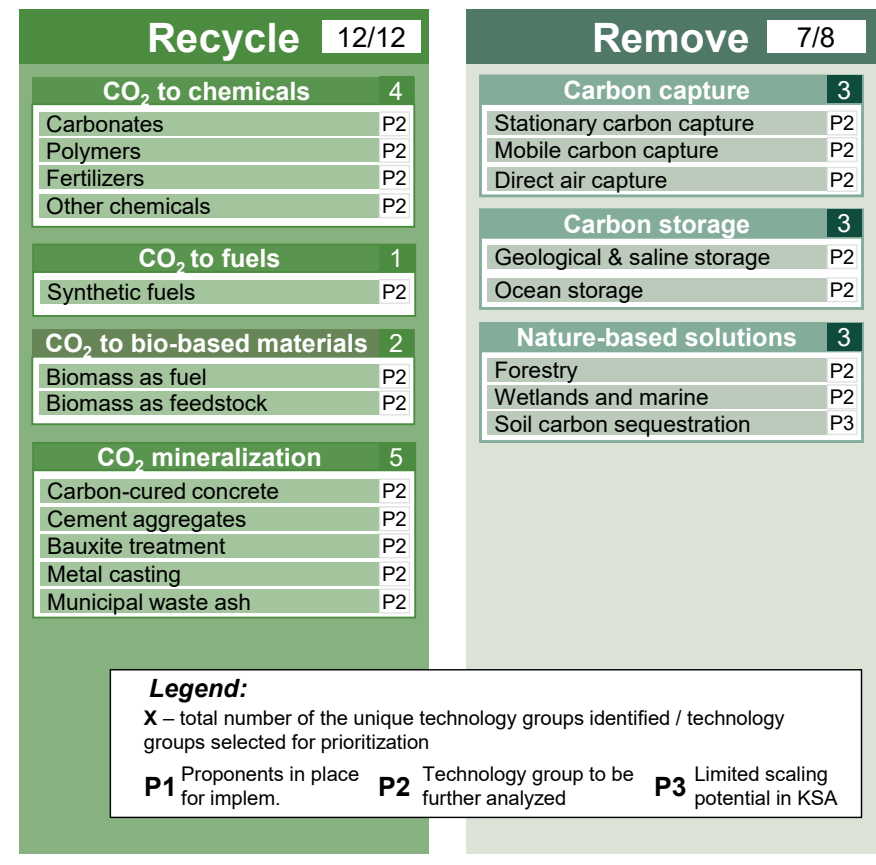

Source: Saudi Arabia's Circular Carbon Economy National Program, 2021.

In terms of data and research, King Abdullah University of Science and Technology (KAUST) has launched the Circular Carbon Initiative. This initiative aims to strengthen research on different aspects of the CCE to support the rapid implementation of related technologies. Ongoing research includes projects on carbon dioxide capture and geological storage, nature-based solutions (NBS), e-fuels and the integration of renewable energy into circular carbon systems.

In the area of CCS, the initiative has quantified major carbon dioxide sources and sinks in Saudi Arabia and concluded that all major source sites of $\mathrm{CO} 2$ (including power and desalination plants, oil refineries and various energy-intensive industrial installations) have significant storage capabilities, in the range of gigatons (see Figure 4). Additionally, KAUST is currently supporting work on site characterization to help understand their permeability, and is seeking to put in place real-time monitoring systems that would allow optimal site selection, among other things.

The university is also conducting research on the lifecycle emissions and other environmental impacts of different reuse and recycle technologies, and estimating NBS carbon storage capacity to identify potential sources of high-quality NBS carbon offsets in the Kingdom. 
Figure 4. Major carbon dioxide sources and sinks in Saudi Arabia.

\section{KSA: $\mathrm{CO}_{2}$ Sources \& Sinks}

\section{Sources}

- 2020 stationary $\mathrm{CO}_{2}$ Emissions: 450 megatons (without blue hydrogen)

- Mainly along the coasts

\section{Sinks}

- Excellent subsurface storage opportunities

- East Coast stacked aquifer

- West Coast rift basins

- Aligned with sources

- Many large capacity structures 12 billion bbl structure $=1$ giga ton $\mathrm{CO}_{2}$ (e.g., Ghawar $=800$ billion bbl)

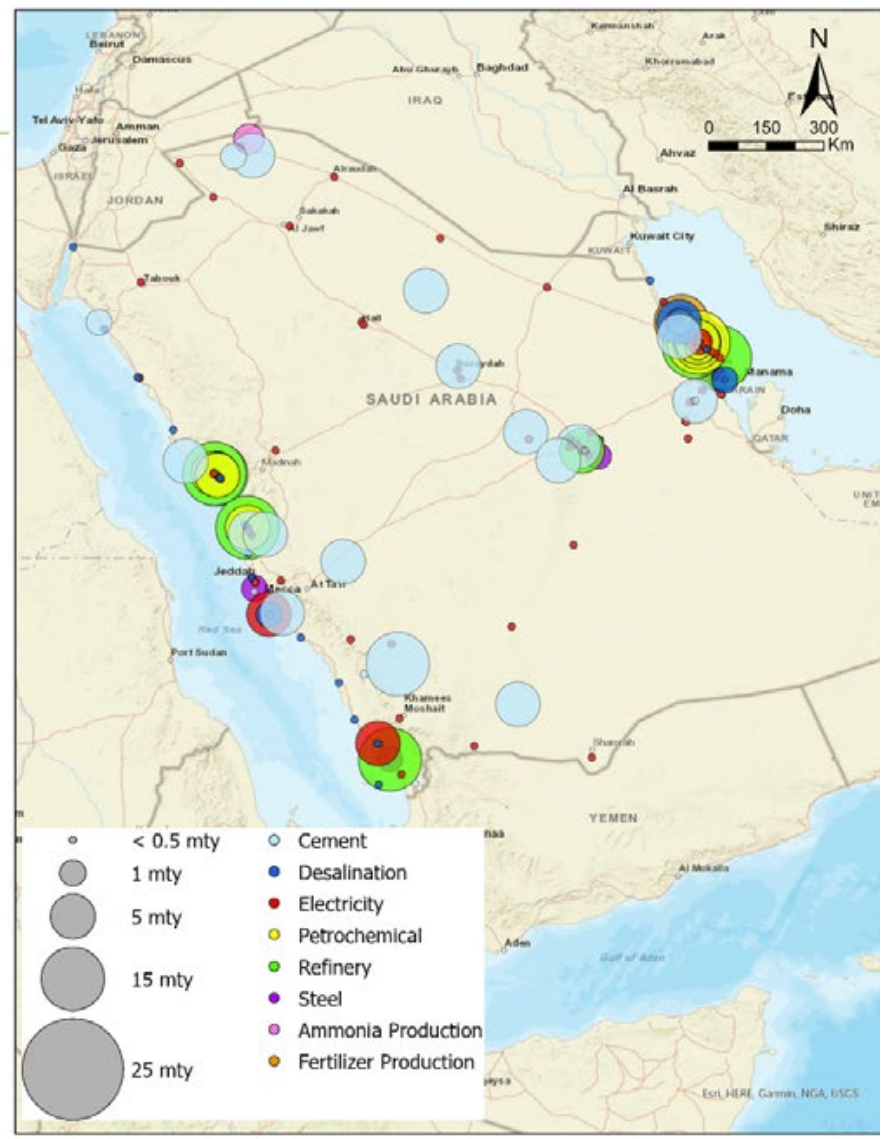

Source: KAUST Circular Carbon Initiative, from Hussein Hoteit et al., 2020. 


\section{Enablers for Future Progress on the CCE}

$\mathrm{T}$

The workshop discussions focused on identifying enablers that can help scale up CCE solutions and technologies, particularly at the company and industry levels. The workshop speakers and participants highlighted the following enablers, among others:

Investments in new technologies and energy sources, including both R\&D and adoption;

Collaborations among governments, businesses and academia;

Advocacy and dialogue in support of the necessary transitions;

Preparing companies for increased environmental, social and governance (ESG) requirements from investors and customers;

Demonstrations of how a CCE approach can unlock cost-effective abatement through practical applications; and

Establishment of measurement and accounting systems to track progress.

One speaker noted that, based on some estimates, up to $70 \%$ of the technologies needed to achieve the Paris Agreement's goals are still in the prototype, demonstration or early adoption stage. Bringing these technologies to market is a major challenge but also provides a great opportunity for industry and academia to collaborate. Collaborations, such as those around pilot projects, can help deliver the R\&D breakthroughs needed to achieve net-zero emissions. Sustained advocacy and dialogue among stakeholders are also crucial to enable 'moonshots,' which will be needed to collectively reach net-zero emissions by mid-century.

Investments that help bring technologies to market are needed from both governments and companies. Saudi Aramco, for example, is investing in R\&D in various technologies that it views as critical for achieving a CCE. Such technologies include advanced materials, e-fuels, carbon dioxide mineralization, hydrogen and direct air capture (Figure 5).

Collaborations that focus on the entire technology value chain can also be impactful and help accelerate uptake. For example, hydrogen is a technology that can support various sectors and industries, including the power and chemical industries. It can also support several of the four Rs, including reduce (green hydrogen) and remove (blue hydrogen). 
Figure 5. Saudi Aramco's flagship CCE R\&D programs.

\section{Saudi Aramco CCE flagship R\&D programs \\ Spillover Reduce, Reuse, Recycle, and Remove CCE Technologies}

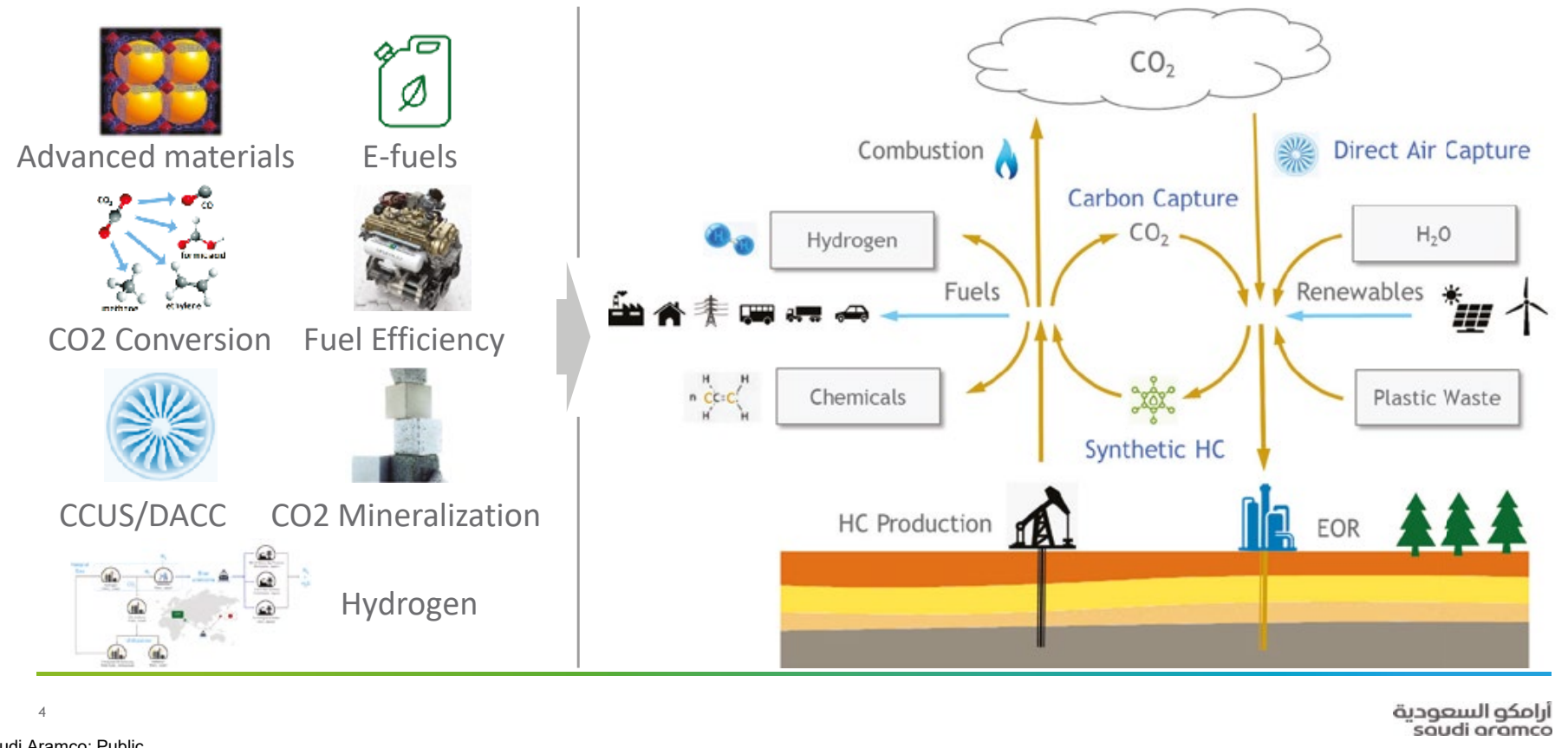

Saudi Aramco: Public

Source: Saudi Aramco, 2021.

For a chemical industry company like SABIC, technologies are also key for supporting carbon circularity. There are two key areas of enablers in this regard: the first relates to decarbonizing energy sources and feedstocks. Here, one of the short-term tasks is electrification. Catalysts and new processes to reduce emissions exist, but many have not yet reached commercial scale. The second area relates to materials produced by the chemical industry: if brought to commercial application, a range of materials could help with the reuse (i.e., CCU) pillar of the CCE, including materials for solar cells and windmills, insulation, low-weight cars and construction.
ESG factors are becoming increasingly important in all industries. For energy and energy-intensive industries, this has been manifested in increasing investor and customer demands regarding companies' carbon footprints and strategies. Workshop participants noted that communication and collaboration across the value chain and among the various players can support raising ambition in these sectors.

The Saudi Public Investment Fund-backed NEOM aims to be a champion of the CCE by demonstrating how it can function in practice, at scale, in an economically feasible manner. The company will seek to play a leading role in Saudi Arabia's 
commitment to developing both a CCE and a circular economy. Related targets are to reach $100 \%$ renewable power supply, eliminate waste to the extent possible and increase the area's biocapacity on an annual basis.

NEOM enjoys the benefit of starting from a clean state, which can help accelerate the scaling up of needed technologies. Amongst other things, the company has developed a Carbon Management
Framework to achieve carbon neutrality as a key enabler for its circular carbon economy (see Figure 6). As part of these efforts, NEOM is working on a greenhouse gas (GHG) inventory system as well as systems for generating and procuring environmental attributes, such as carbon offsets. These efforts, in turn, are helping to develop capacity around national-level emissions accounting and carbon monetization systems in the relevant government entities.

Figure 6. NEOM's carbon management framework.

\section{* THE NEOM CARBON MANAGEMENT FRAMEWORK INTEGRATES AND GOVERNS SIX COMPONENTS IN A SYSTEMATIC APPROACH} 6. C O M M U N I C A T E
Communication of NEOMs journey towards
achieving a Circular Carbon Economy

5. CERTIFY

Creation of an auditable and replicable certification standard for GHG Inventories and carbon neutrality

$$
\text { Procurement of offsets to achieve NEOMs Circular Carbon }
$$
Economy Vision throughout the development phase

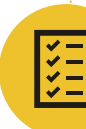

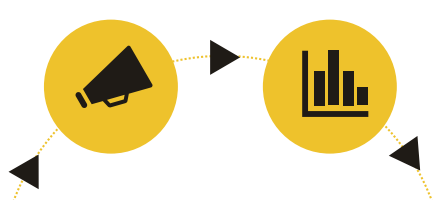

1. MEASURE

Monitoring, Reporting, and Verification of NEOMs greenhouse gas emissions through a GHG Inventory System

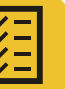

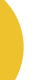
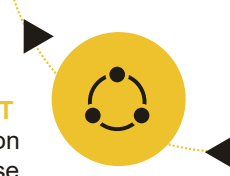

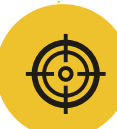

2. $\mathrm{C} O \mathrm{M} M \| \mathrm{T}$

Definition of realistic $\mathrm{GHG}$ reduction targets to drive NEOMs strategy towards a Circular Carbon Economy (carbon neutral)

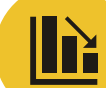

3. REDUCE

Generation of NEOM based offsets through registration of green initiatives under internationally accredited certification schemes

\section{...AS A KEY ENABLER FOR NEOM'S CIRCULAR CARBON ECONOMY}

Source: NEOM, 2021. 


\section{Areas for Further Work on CCE Metrics and Tools to Support Implementation}

D espite the G20's endorsement, the CCE concept is still largely unknown outside of Saudi Arabia. Progress on the CCE National Program will demonstrate in concrete ways how the concept can be operationalized as a national-level mitigation framework that ensures economic development while reducing emissions in line with the Paris Agreement's goals. In addition, workshop participants agreed that metrics can help to clarify the CCE concept and extend its utility and application beyond Saudi Arabia.

The CCE framework does not direct countries toward specific ways to reduce emissions. Thus, it can provide narratives that align with individual countries' resource endowments and related strengths, past development pathways, and future goals and targets. Metrics for the CCE therefore need to accommodate a broad variety of mitigation options and country circumstances.

Workshop participants highlighted the need for specific metrics and tools to help governments and other stakeholders with data-driven decision-making around CCE technologies and policies. Making existing data available to researchers and other stakeholders is a crucial first step in strengthening the science-policy interface. The lack of data and data-oriented policy tools, such as accounting frameworks or standards, pose challenges in many areas. These areas, in which researchers can in many cases provide support, include:

Data on other GHGs, including methane, nitrous oxide and hydrofluorocarbons;

Lifecycle analyses of various CCE technologies;

Carbon circularity industry standards;
Data and metrics for measuring circularity performance and potential in the hydrocarbon sector and among oil companies;

Data and metrics related to carbon (capture and) utilization; and

Data and studies on the overall cost of mitigation, including at the economy level and for CCE scenarios with different combinations of circularity technologies.

Two points from this list merit further emphasis. First, data on CCU are lacking largely because many technologies for retaining large amounts of carbon over long periods of time are not yet commercially available. However, research could help even in the current early stages by quantifying the emissions reductions achieved through different CCU technologies, including fuels, chemicals and building materials (IEA 2020).

The absence of large-scale CCU production and the related scarcity of data and metrics limit the CCE's applicability as a performance measurement framework. In the near term there will be no opportunities for tangible measurements under one or more pillars of the CCE, depending on the CCE taxonomy adopted - one leading CCE taxonomy classifies CCU under 'reuse' whereas another relates CCU to both the 'recycle' and 'reuse' pillars.

Second, many participants emphasized the need to measure the costs of different mitigation technologies to ensure cost-effective abatement, particularly in hard-to-abate sectors. Understanding costs can also help governments identify industries and areas with competitive advantages and target their investments accordingly. Information about costs can also help companies make business 
cases for various circularity solutions and make decisions relating to carbon offsetting.

Finally, participants emphasized that a core value proposition of the CCE is that it can ensure the most cost-effective mitigation pathways in various country contexts. The CCE's proponents stress that according to global climate models, exclusively focusing on the reduce pillar (i.e., renewable energy and energy efficiency) results in costlier net-zero pathways. This is particularly the case for hard-to-abate sectors (Goldman Sachs 2019). Workshop participants suggested that measuring the average cost of mitigation across all sectors of an economy could be a good way to demonstrate how higher contributions from the other pillars of the CCE (recycle, reuse and remove) can deliver more cost-effective pathways to carbon circularity and net-zero emissions. 


\section{References}

Goldman Sachs. 2019. Carbonomics: The Future of Energy in the Age of Climate Change. December 11.https://www.goldmansachs.com/insights/pages/ gs-research/carbonomics-f/report.pdf

G20 Energy Ministers. 2020. "G20 Energy Ministers Communiqué." September 27-28. http://www. g20.utoronto.ca/2020/G20SS_Energy_Ministers_ Meeting_Communique.pdf

G20 Saudi Arabia. 2020. "Leaders' Declaration." G20 Leaders' Summit, Riyadh, November 21-22. http://www.g20.utoronto.ca/2020/ G20_Riyadh_Summit_Leaders_Declaration_EN.pdf Hepburn, Cameron, Ella Adlen, John Beddington, Emily A. Carter, Sabine Fuss, Niall Mac Dowell, Jan C. Minx, Pete Smith, and Charlotte K. Williams. 2019. "The Technological and Economic Prospects for CO2 Utilization and Removal." Nature 575:8797. doi:10.1038/s41586-019-1681-6. https://doi. org/10.1038/s41586-019-1681-6

International Energy Agency (IEA). 2020. "Reuse: Carbon Reuse.” G20 Circular Carbon Economy Guide Report. https://www.cceguide.org/wp-content/ uploads/2020/08/04-IEA-Reuse.pdf

KAPSARC. 2020. "CCE Guide: Overview. A guide to the circular carbon economy (CCE)." https://www. cceguide.org/guide/
Luomi, Mari, Fatih Yilmaz, Thamir Alshehri, and Nicholas Howarth. 2021. "The Circular Carbon Economy Index - Methodological Approach and Conceptual Framework." KAPSARC Methodology Paper, May. Riyadh: KAPSARC. Doi: 10.30573/KS-2021-MP01.https://doi.org/10.30573/ks--2021-mp01

Williams, Eric. 2019. "Achieving Climate Goals by Closing the Loop in a Circular Carbon Economy." KAPSARC Instant Insight, KS--2019-II10, November. Riyadh: KAPSARC. https://www.kapsarc.org/ research/publications/achieving-climate-goals-byclosing-the-loop-in-a-circular-carbon-economy/ 


\section{About the Workshop}

APSARC held a virtual workshop on June 6 , 2021, with 50 stakeholders from the government, industry, and academic and research institutions in Saudi Arabia. The workshop had two purposes. The first was to initiate a discussion on a data-driven approach for measuring the CCE. The second was to collect inputs to inform the design of the index's structure and indicators. A KAPSARC Methodology Paper (Luomi et al. 2021) was made available to participants ahead of the session to help guide the discussions.

Speakers at the workshop were:

Ahmad O. Al Khowaiter - Chief Technology Officer, Saudi Aramco

Fahad Al-Sherehy - Vice President Energy Efficiency and Carbon Management, SABIC

Ahmed Al-Zahrani - Deputy Minister for Development and Excellence, Ministry of Energy of Saudi Arabia
Fahad Alajlan - Program Director, Oil Sustainability Program, Ministry of Energy of Saudi Arabia

Thamir Alshehri - Research Associate, KAPSARC

Fahad Alturki - Vice President of Research, KAPSARC

Jorge Gascon - Circular Carbon Initiative Lead, Director of KAUST Catalysis Center, KAUST

Mari Luomi - Research Fellow II, KAPSARC

Jens Madrian - Executive Director, NEOM Energy

Adam Sieminski - President, KAPSARC

Fatih Yilmaz - Senior Research Associate, KAPSARC 


\section{Notes}

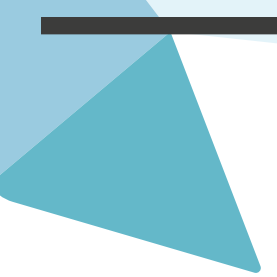


Notes

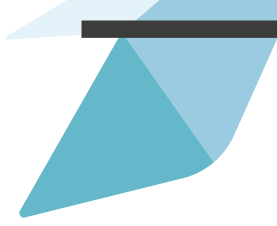




\section{Notes}

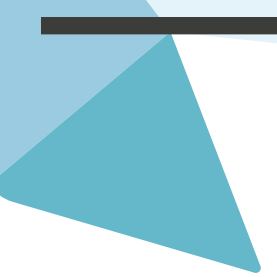




\section{About the Team}

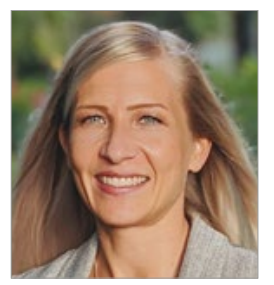

\section{Mari Luomi}

Mari is Research Fellow II in KAPSARC's Climate and Environment program. She is a policy-oriented social scientist who has been studying climate change, energy transitions and sustainable development policy in the Gulf and globally for close to 15 years. She has worked for other leading energy, sustainable development and foreign policy research institutions, including the Oxford Institute for Energy Studies, the International Institute for Sustainable Development (Earth Negotiations Bulletin), Georgetown University, the Finnish Institute of International Affairs, and the Emirates Diplomatic Academy.

Mari holds a master's degree in political science and international politics from the University of Helsinki and a Ph.D. in Middle Eastern Studies from Durham University.

In addition to a broad research publications portfolio, she has substantial experience in executive training, presentations, policy advisory, and reporting services for multilateral environmental negotiations.

\section{Fatih Yilmaz}

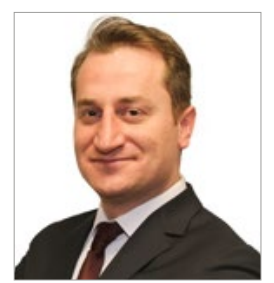

Fatih is Senior Research Associate in KAPSARC's Energy Transitions and Electric Power program. His current research agenda aims to enhance our understanding of the financial and economic consequences of the global energy transition toward renewables, and to design effective policies to balance financial risks and growth prospects.

Before joining KAPSARC, Fatih worked as an economist in the Structural Economic Research Department of the Central Bank of the Republic of Turkey, where he was involved in the research and the design of policies for the private and banking sectors. He has also worked as a consultant for the World Bank, and took responsibilities in various consulting projects for the Canadian and Turkish Governments. Fatih spent a year as an assistant professor at the ADA University, Azerbaijan, and worked as a graduate assistant at the University of Calgary and at the Western Illinois University, where he taught several courses in economics and econometrics.

Fatih has authored various academic and policy articles and book chapters. He has helped organize conferences and workshops and has acted as a referee for many academic journals. 


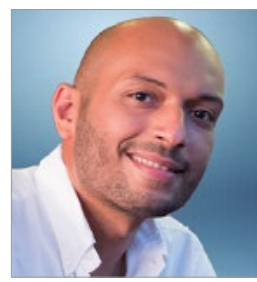

Thamir Alshehri

Thamir is Research Associate in KAPSARC's Energy Transitions and Electric Power program. He is currently focused on creating data-driven tools to identify and evaluate different energy market scenarios, as well as using 'big data' technologies to better understand the impact of consumer behavior and the environment on energy consumption. Thamir is interested in using technologies to facilitate better energy public policy and energy economical systems.

Thamir also acts as an advisor to the broader energy ecosystem in Saudi Arabia, particularly in the areas of clean energy transitions, sustainability, and carbon emissions management. He is also a member of the Technology and Economic Assessment Panel, United Nations Environment Programme (UNEP).

He previously worked as a lecturer in Australia and has entrepreneurial and industrial experience from working on award-winning projects such as the Burj Khalifah Building Management System. 


\section{About the Project}

The Circular Carbon Economy (CCE) Index project seeks to expand and add rigor to the conceptual basis of CCE by developing a robust quantitative framework to measure country performance and progress toward CCEs.

The CCE Index project, which will run through 2021, consists of various components, including a KAPSARC Methodology Paper published in spring 2021 that provides a conceptual-methodological framework for the CCE Index and for related expert and stakeholder consultations.

The results of the first edition of the CCE Index, aimed to be finalized in time for the 2021 UN Climate Change Conference, will be published in a report containing the results for a selected group of countries, such as the Group of Twenty (G20) and several hydrocarbon exporting countries. A web-based dashboard is also planned for easier visualization of the results, along with other web-based tools.

The CCE Index is a composite indicator measuring various dimensions of the CCE in a national context across countries. For each country, it provides a snapshot of data based on the latest available year and shows indicator-based trends over a period of years.

The CCE Index has two main aims: first, it is intended as a vehicle to promote the concept of the CCE and the idea of adopting a holistic approach to managing emissions across energy systems and economies. Second, the Index is intended to enable further discussions around ways to identify, measure and compare countries' strengths and weaknesses in terms of the CCE, and to help pinpoint areas where progress is already well underway and where further policy efforts are needed.

The CCE Index, and related stakeholder consultations, are also intended to support discussions within Saudi Arabia on ways to promote and advance the CCE, including by providing inputs into and drawing from work on the CCE National Program announced in November 2020 by King Salman bin Abdulaziz Al Saud.

The project's audience and stakeholders comprise domestic and international energy and climate change actors in government, the private sector, international organizations, research institutions and civil society. 
INAPSARC

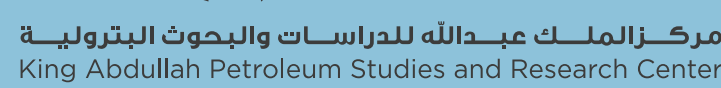

www.kapsarc.org 